
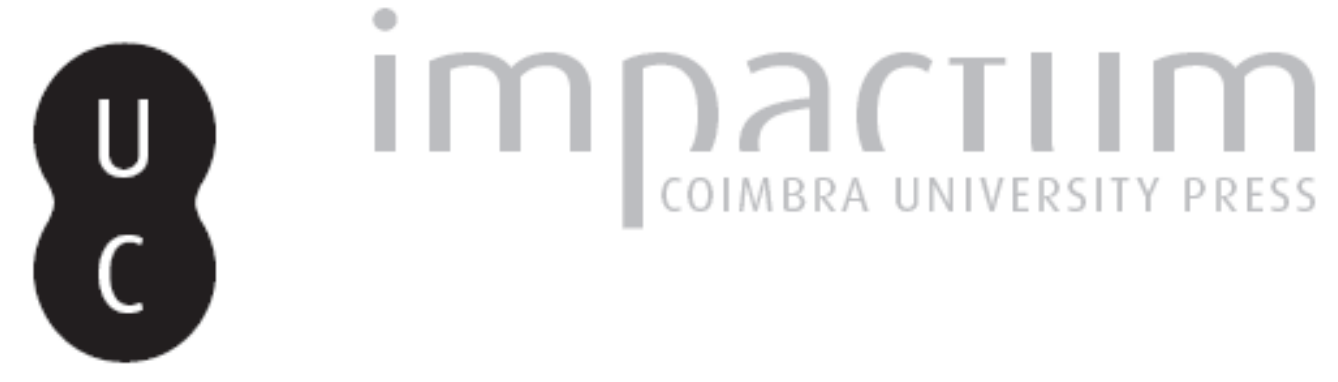

\title{
Macedónios, xenoi, misthophoroi e pantodapoi na guerra dos diadochi
}

Autor(es): $\quad$ Sant'Anna, Henrique Modanez de
Publicado por: Associação Portuguesa de Estudos Clássicos; Instituto de Estudos Clássicos

URL persistente:

URI:http://hdl.handle.net/10316.2/30390

DOI:

DOI:http://dx.doi.org/10.14195/0872-2110_52_9

Accessed : $\quad$ 26-Apr-2023 15:15:58

A navegação consulta e descarregamento dos títulos inseridos nas Bibliotecas Digitais UC Digitalis, UC Pombalina e UC Impactum, pressupõem a aceitação plena e sem reservas dos Termos e Condições de Uso destas Bibliotecas Digitais, disponíveis em https://digitalis.uc.pt/pt-pt/termos.

Conforme exposto nos referidos Termos e Condições de Uso, o descarregamento de títulos de acesso restrito requer uma licença válida de autorização devendo o utilizador aceder ao(s) documento(s) a partir de um endereço de IP da instituição detentora da supramencionada licença.

Ao utilizador é apenas permitido o descarregamento para uso pessoal, pelo que o emprego do(s) título(s) descarregado(s) para outro fim, designadamente comercial, carece de autorização do respetivo autor ou editor da obra.

Na medida em que todas as obras da UC Digitalis se encontram protegidas pelo Código do Direito de Autor e Direitos Conexos e demais legislação aplicável, toda a cópia, parcial ou total, deste documento, nos casos em que é legalmente admitida, deverá conter ou fazer-se acompanhar por este aviso.

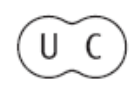




\section{Boletim de}

\section{Estudos Clássicos}

Associação Portuguesa de Estudos Clássicos Instituto de Estudos Clássicos

Coimbra

Dezembro de 2009 


\section{MACEDÓNIOS, XENOI, MISTHOPHOROI E PANTODAPOI NA GUERRA DOS DIADOCHI}

Embora a continuidade dos exércitos cívicos no período subsequente à morte de Alexandre seja digna de nota, é facto indiscutível que o mundo helenístico assistiu, maioritariamente, à redução dos exércitos ao tipo profissional: o mercenário (xenos ou misthophoros) ${ }^{1}$. De facto, as condições de recrutamento variaram de acordo com as tradições locais e com os grupos étnicos disponíveis em tais regiões, mas a guerra helenística no tempo dos Diadochi assistiu à preferência pela incorporação de tropas inimigas derrotadas na condição de mercenários e ao tratamento mercenário dado a todos os soldados, não importando a sua ascendência ou as condições iniciais de seu recrutamento. Diante desta constatação, torna-se relevante mapear - e distinguir - os termos que aparecem em Diodoro, nossa principal fonte para o período, nesta parte servindo-se de Hierónimo de Cárdia, quando a classificação das tropas profissionais pagas vem à tona, isto é, no momento em que os Diadochi empregam grandes exércitos mercenários na luta sucessória.

Ao lado dos mercenários conhecidos desde a campanha de Alexandre (agrianos, trácios, tessálios, cretenses, entre outros), os macedónios desempenharam uma função de grande importância na composição dos exércitos helenísticos: a falange representava a força de apoio, tornando-se responsável em boa medida pela manutenção do centro da formação, ao passo que a cavalaria e os elefantes de combate (quando disponíveis) realizavam a ofensiva nas alas e procuravam decidir a peleja.

\footnotetext{
${ }^{1}$ Uma diferença deve ficar clara, qual seja, aquela entre os profissionais pertencentes aos chamados Batalhões Sagrados (hieroi lochoi), grupos citadinos de elite criados nos moldes espartanos durante o período clássico, e os profissionais propriamente mercenários, para quem a guerra havia se tornado uma profissão e cujo serviço era oferecido para contratantes diversos, independentemente da causa pela qual a guerra era travada. Esta distinção, no entanto, tenderá a desaparecer no período helenístico.
} 
Em Diodoro ${ }^{2}$, por exemplo, após desferir um ataque inesperado ao espaço aberto pela marcha irregular da infantaria de Êumenes, Antígono conseguiu, na batalha de Paraitacene (317 a.C.), alinhar novamente a sua falange ao pé do monte, para onde os soldados haviam se retirado, reestruturando boa parte da linha defensiva de seu exército. Neste caso, a reorganização da infantaria macedónica em campo de batalha teria assegurado, por um lado, a vitória do comandante aparentemente derrotado e, por outro, devido à irregularidade da marcha dos infantes inimigos, a derrota daquele que pensava ter vencido o confronto.

Sendo os macedónios de reconhecida importância nos primeiros 20 anos subsequentes à morte de Alexandre, o questionamento sobre a multiplicação de suas aparições no relato de Diodoro se faz necessário. Por que razão as referências a eles aumentaram no período de divisão das chamadas "tropas nacionais" entre os generais de Alexandre, o que forçosamente teria reduzido o seu número em cada um dos exércitos que lutavam entre si pela supremacia militar?

Griffith $^{3}$ e Launey ${ }^{4}$ apresentaram explicações idênticas para tal evento. Em primeiro lugar, dada a impossibilidade dos números apresentados por Diodoro ${ }^{5}$ para as tropas macedónicas, o ponto de partida se torna a valoração técnica adquirida por makedon no séc.III a.C., especialmente no Egito, ou seja, o termo deixou de ser "uma garantia de proveniência geográfica" 6 e passou a designar unicamente um "cavaleiro ou soldado de infantaria pesadamente armados, segundo as tradições macedónicas”7.

Notamos, então, a fusão da referência étnica com a valoração técnica do termo makedon, o que por vezes torna impossível a identificação exata dos batalhões formados unicamente por veteranos de Alexandre ou por novos macedónios, exceto quando os primeiros são mencionados como

2 Diodoro, Biblioteca Histórica, 19.27-31.

3 G.T. Griffith, The Mercenaries of the Hellenistic World, Chicago, Ares, 1935, p. 41.

4 Marcel Launey, Recherches sur les armées hellénistiques, 2 vols., Paris, Boccard, 1949, vol.1, pp. 290-93.

5 Diodoro, Biblioteca Histórica 18.30.

6 Launey, op. cit. p. 290.

7 Launey, op. cit. p. 293. 
argyraspides, em contraposição àqueles provenientes das satrapias e armados com equipamento macedónico.

Outras referências relevantes nos exércitos helenísticos são os mercenários gregos propriamente ditos, conhecidos como xenoi, os misthophoroi, e as tropas asiáticas mistas ou pantodapoi, recrutadas nas províncias e listadas entre os demais soldados, servindo ora como cavaleiros e arqueiros, ora como infantaria de pouca utilidade, se comparada àquela dos mercenários gregos. Deve-se observar que estas não são categorias necessariamente excludentes, uma vez que encontramos, por exemplo, em Diodoro ${ }^{8}$, "três mil pantodapoi armados com equipamento macedónico", o que sugere uma possibilidade dupla de tratamento. Apenas os xenoi se diferenciam claramente dos misthophoroi: ambos costumam ser traduzidos como mercenários, mas os primeiros são quase sempre dispostos como infantaria pesada (na linha de frente), enquanto os últimos fazem referência às tropas levemente armadas e constituídas por pantodapoi ou por outras tropas asiáticas.

Vejamos a organização do exército de Antígono em 317 a.C., de acordo com Diodoro $^{9}$, num trecho esclarecedor quanto à temática em questão:

Quanto à infantaria, mais de nove mil mercenários (oi ǵćvot) foram dispostos à frente; próximo a eles [foram dispostos] três mil lícios e panfílios e em seguida mais de oito mil tropas mistas armadas com equipamento

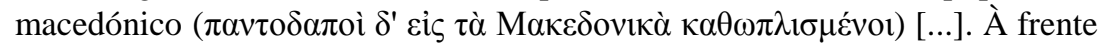
dos cavaleiros na ala direita adjacente à falange estavam 500 mercenários de origem mista ( $\mu 1 \sigma \theta 0 \varphi$ óoı $\pi \alpha v \tau o \delta \alpha \pi \circ i)$ [...].

Há dois tipos de mercenários na passagem acima. Os primeiros, em número de 9.000, eram claramente soldados de infantaria pesadamente



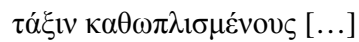

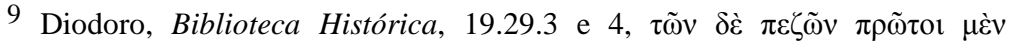

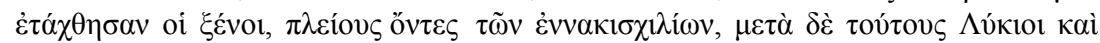



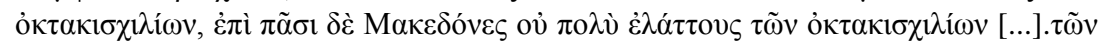

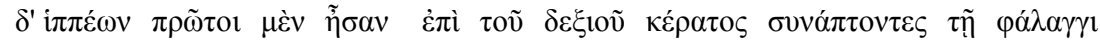

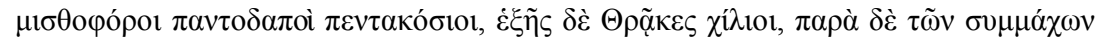
$\pi \varepsilon v \tau \alpha \kappa o ́ \sigma 101[\ldots]$ 
armados, hoplitas mercenários. Os últimos, dispostos como cavaleiros, eram também tropas mercenárias, mas de uma categoria diferente, não só por combaterem a cavalo, mas por serem asiáticos. Noutras palavras, mercenários asiáticos são tão mercenários quanto os que advêm da Grécia, porém a distinção estabelecida pelo uso dos dois termos deve ser notada, ainda que não possamos mensurar qualquer distinção no tratamento dado a ambos por parte do empregador.

Os pantodapoi são comumente citados por Diodoro, como exposto acima, mas a sua participação em batalha não tem lugar de destaque na narrativa do historiador siciliano, da mesma forma que os mercenários no relato de Arriano sobre a campanha de Alexandre. As tropas de origem étnica bem definida, por sua vez, não constituíram uma exceção a essa regra, a não ser por aparições velozes e escassas, mas por vezes determinantes, como no caso dos capadócios ${ }^{10}$.

A terminologia das tropas, portanto, ilustra que a heterogeneidade dos termos indica também a pluralidade dos soldados no que respeita a sua ascendência, mas o tratamento dado a eles não se diferencia ao longo do processo de incorporação por meio do suborno ou da aquisição após a batalha. Por fim, macedónios, xenoi, misthophoroi e pantodapoi ocupam lugares específicos na guerra dos Diadochi, não podendo ser confundidos entre si, mas a universalidade da sua condição mercenária não deve também ser negligenciada, se se tem em consideração a forma como foram empregados nos confrontos armados ao longo dos primeiros vinte anos da época helenística.

HENRIQUE MODANEZ DE SANT'ANNA

10 Diodoro, Biblioteca Histórica, 18.30. 